\title{
Lived Experiences of Negative Symptoms in First-Episode Psychosis: A Qualitative
}

\section{Secondary Analysis}

Brioney Gee ${ }^{1 *}$, Jo Hodgekins ${ }^{1}$, Anna Lavis², Caitlin Notley ${ }^{1}$, Max Birchwood ${ }^{3}$, Linda

Everard $^{4}$, Nick Freemantle ${ }^{5}$, Peter B. Jones ${ }^{6}$, Swaran P. Singh ${ }^{3}$, Tim Amos ${ }^{7}$, Max Marshall ${ }^{8}$, Vimal Sharma ${ }^{9}$, Jo Smith ${ }^{10}$, David Fowler ${ }^{11}$

${ }^{1}$ Norwich Medical School, University of East Anglia, Norwich, UK.

${ }^{2}$ University of Birmingham, Edgbaston, Birmingham, UK.

${ }^{3}$ University of Warwick, Gibbet Hill Road, Coventry, UK.

${ }^{4}$ Birmingham and Solihull Mental Health NHS Foundation Trust, UK.

${ }^{5}$ University College London, Gower St, London, UK.

${ }^{6}$ University of Cambridge, Cambridge, UK; Cambridgeshire and Peterborough NHS

Foundation Trust, Cambridgeshire, UK.

${ }^{7}$ University of Bristol, Bristol, UK.

${ }^{8}$ University of Manchester, Oxford Road, Manchester, UK.

${ }^{9}$ University of Chester, UK; Cheshire and Wirral Partnership NHS Foundation Trust, UK.

${ }^{10}$ University of Worcester, Worcester, UK.

${ }^{11}$ University of Sussex, Brighton, UK.

\section{*Address for correspondence:}

Dr Brioney Gee

Norwich Medical School, University of East Anglia,

Norwich, UK. NR4 7TJ

Email: brioney.gee@uea.ac.uk Tel: +44(0)1603201455

Word Counts: Abstract $=206 ;$ Text body $=3055$ 


\section{Acknowledgments}

We thank the participants who shared their experiences with us, the researchers who conducted the interviews, members of the Super EDEN Lived Experiences Advisory Panel and the Early Intervention teams who supported this research. We thank the UK Mental Health Research Network for their support in case finding and follow-up. We would like to acknowledge the contribution to EDEN of Prof. Helen Lester, co-Chief Investigator on National and Super EDEN, who sadly passed away before this paper was produced.

Super EDEN was funded by the National Institute for Health Research (NIHR) under the Programme Grants for Applied Research programme (RP-PG- 0109-10074). MB, Chief Investigator of Super EDEN, is part-funded by NIHR CLAHRC West Midlands; SPS is part funded by the NIHR through the Collaborations for Leadership in Applied Health Research and Care for the West Midlands; and PBJ is part funded by the NIHR CLAHRC East of England. The views expressed are those of the authors and not necessarily those of the NHS, the NIHR or the Department of Health. 


\begin{abstract}
Aim: Exploring how negative symptoms are experienced and understood by individuals with lived experience of psychosis has the potential to offer insights into the complex psychosocial processes underlying negative symptom presentations. The aim of the current study was to investigate lived experiences of negative symptoms through secondary analysis of interviews conducted with individuals recovering from first-episode psychosis.
\end{abstract}

Method: Transcripts of in-depth interviews with participants $(n=24)$ recruited from Early Intervention in Psychosis services were analysed thematically with a focus on participants' experiences and personal understandings of features corresponding to the negative symptoms construct.

Results: Descriptions of reductions in expression, motivation and sociability were common features of participants’ accounts. Several participants described the experience of having difficulty interacting as like being a 'zombie'. Some participants experienced diminished capacity for emotion, thought or drive as underlying these experiences. However, participants typically attributed reductions in expression, motivation and sociability to medication sideeffects, lack of confidence or active avoidance intended to protect them from rejection or ridicule, sometimes linked to internalised stigma.

Conclusions: Personal accounts of experiences of reduced expression, motivation and sociability during first-episode psychosis highlight the personal meaningfulness and role of agency is these features, challenging the framing of negative symptoms as passive manifestations of diminished capacity.

Key words: lived experience; negative symptoms; psychosis; qualitative research; thematic analysis 


\section{Introduction}

Reductions in expression, motivation and sociability are observed across the spectrum of functional psychoses (Lyne et al., 2012). These features consistently coalesce in factor analytic studies (Blanchard \& Cohen, 2006) and are collectively referred to as negative symptoms. Negative symptoms are a significant predictor of poor recovery from first-episode psychosis (Austin et al., 2013; Hodgekins et al., 2015; Singh et al., 2000) and are a treatment priority for many service-users (Sterk, Winter van Rossum, Muis, \& de Haan, 2013). However, the development of effective treatment options for negative symptoms is hindered by still limited understanding of their underlying mechanisms (Velthorst et al., 2015).

The importance of seeking to understand the experience of psychosis from the perspective of those with lived experience is increasingly accepted (Boydell, Stasiulis, Volpe, \& Gladstone, 2010; McCarthy-Jones, Marriott, Knowles, Rowse, \& Thompson, 2013). Qualitative methods have been used to provide insights into the experience of positive symptoms (Engqvist \& Nilsson, 2013; Le Lievre, Schweitzer, \& Barnard, 2011; Luhrmann, Padmavati, Tharoor, \& Osei, 2015) and the personal meanings attributed to them (Hirschfeld, Smith, Trower, \& Griffin, 2005; Larsen, 2004; Werbart \& Levander, 2005). However, how negative symptoms are experienced and understood by individuals with lived experience has so far received little research attention.

Understanding personal constructions of negative symptoms is important given the potential for such understanding to facilitate improved intervention by offering clues to the mechanisms that underpin these debilitating symptoms. The current study aimed to explore how negative symptoms are experienced and understood by those with lived experience of 
first-episode psychosis using thematic analysis of interviews conducted with individuals recruited from UK Early Intervention in Psychosis (EIP) services.

\section{Methods}

\section{Context}

Interviews were conducted as part of the Super EDEN study (Chief Investigator, MB; Qualitative Lead, AL), a follow-up to the National EDEN evaluation of UK EIP services (Birchwood et al., 2014). Participants in the study's qualitative component $(n=207)$ were invited to be interviewed every 12 months during the two year follow-up period. The study obtained NHS ethical approval before commencing and adhered to Good Clinical Practice guidelines.

\section{Participants and Sampling}

Participants were included in Super EDEN on the basis of having met the acceptance criteria for a participating EIP service; no additional inclusion criteria were imposed. The acceptance criteria of the participating services were in line with the Department of Health’s Policy Implementation Guidelines for EIP services and included: presence of a psychotic disorder consistent with an ICD-10 diagnosis F20-29; aged 14 - 35 years; and no previous treatment for a psychotic episode.

A purposive sample of transcripts of interviews with Super EDEN participants who participated in the qualitative sub-study described above was defined for the purposes of the 
current study. In a prior study (Gee et al., 2016), latent class growth analysis was used to categorise EDEN participants into latent classes according to the severity and stability of their early negative symptoms. To ensure the purposive sample for the current study included participants who had presented with negative symptoms of the full range of severity and stability observed in the wider cohort, participants were selected from across the latent classes identified. The participants sampled from within each latent class were selected based on their demographic characteristics to maximise variation in gender, ethnicity and study site. Participant demographic and clinical characteristics are presented in Table 1. Pseudonyms are used to protect participant anonymity.

\section{[Insert Table 1]}

\section{Data Collection}

The interviews that generated the data explored in this secondary analysis explored a range of topics, including symptoms, relationships, treatment and recovery. Motivated by a desire to prioritise the interests and concerns of participants, and underpinned by the interpretive qualitative framework of medical anthropology (Bernard, 2006; Lambert \& McKevitt, 2002), interview schedules were developed iteratively; schedules were amended to reflect themes participants had guided earlier interviews towards. Schedules were developed in collaboration with a panel of young people with personal experience of psychosis.

Written, informed consent was sought before interviews commenced and reconfirmed verbally after completion. Interviews were conducted by trained research assistants, either in the participant's home or a community venue according to participant preference. They were 
designed to take around one hour but varied in length according to the level of detail participants chose to provide. Interviews were audio-recorded and transcribed verbatim.

\section{Analysis}

Qualitative secondary data analysis comprises utilising previously collected qualitative data to answer new or additional research questions (Heaton, 2004). Qualitative secondary analysis can generate new insights in a number of ways, including by 'prioritising a concept or issue that was present in the original data but was not the analytical focus' and selecting 'purposively from the sample used in the original study'(Irwin \& Winterton, 2011). These strategies were used in tandem in the current study.

A thematic approach to analysis was adopted (Braun \& Clarke, 2006; Notley, Green, \& Marsland, 2014). Informed by critical realism, which recognises that each individual has a unique experience of reality (Danermark, Ekström, Jakobsen, \& Karlsson, 2002), we sought to understand participants' perspectives through close engagement with individual narratives. Consequently, analysis was data-driven with coding drawing on the language used by participants themselves rather than an a priori analytic framework. The coding structure was refined and themes developed with the aid of qualitative data analysis software NVivo (QSR International, 2012). All transcripts were analysed by the first author and a small number of randomly selected transcripts independently analysed by the second author as a cross-check on the quality of the analysis. 


\section{Results}

The phrase 'negative symptoms' featured in the transcripts only once. However, descriptions of experiences corresponding to the negative symptom construct, including diminished expression, motivation and sociability, featured in all but four participants' accounts. Five themes in participants' constructions of these experiences were identified: "like a zombie", diminished internal experience, medication side-effects, “a confidence thing” and active avoidance.

\section{"Like a zombie"}

Some participants recounted difficulties interacting with others during their episode of psychosis, often recalling not talking as much as usual. Some described being unable to express appropriate emotions. The simile 'like a zombie’ was used by several participants when describing these experiences:

\footnotetext{
"I wasn't moving, I was sitting down ... I wasn't talking. I was just like, you know, like a zombie, just sitting there ... I'd just sit down and not interact with anyone". Aisha, Birmingham

"I was just sitting all day and not speaking at all and not showing any reaction when people were talking to me ... I didn’t even like say anything when my sister had a baby. I wasn't even interested. I was just like a zombie". Jennifer, Lancashire
}

Several participants indicated that they felt remote from themselves as well as others during the experience. For instance, Callum commented that he was not himself ("I'm not me”) whilst in this zombie-like state. Thus, for some participants, disruption in the ability to interact with others appears to have led to discontinuity in identity. 


\section{Diminished internal experience}

A small number of participants reported that reduced expression was a result of reduced internal experience. For instance, Clara explained that she struggled to communicate because she felt 'numb' and 'blocked':

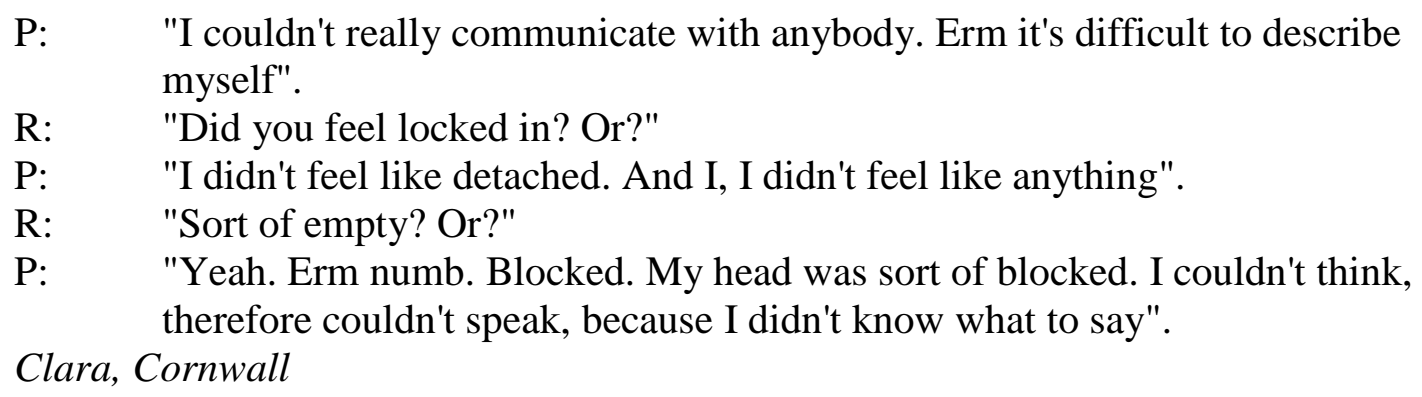

Another participant explained that her lack of emotional expression was symptomatic of a long standing absence of strong emotions, leading to a feeling of being disconnected from her body:

"Do you know that twin towers, when it crashed, I didn’t care. I sat watching it, I was like, oh yeah boring. But now, when I watch programmes on it, I was nearly crying because I was like oh it's so dramatic and emotional and everything. But I remember distinctly when it happened, I just sat there staring ... I didn’t have any feelings for any of it. It was horrible. It was like I'd been possessed by a demon or something, it was really weird. It was like I wasn’t even in my own body".

Jennifer, Lancashire

Similarly, some participants explained decreased motivation as a consequence of a profound reduction in their enthusiasm for life, aligning with characterisations of negative symptoms as indicative of reduced drive and hedonic capacity:

"you do feel like you've had so much sucked out of you that, it's like that inner child it's a bit like someone's taken it by the neck, strangled it, it's just survived and then shaken it again and then said, right your life's never going to be the same again ... we 
go to the park, we go out for lunch, we go into town and go to groups or whatever and I do do that but just not with as much gusto as I did before".

Isabella, Cambridgeshire

\section{Medication side-effects}

Participants most commonly understood decreased expression, motivation and sociability to be side-effects of prescribed medications. Participants commented that anti-psychotic medications decreased their drive to engage in activities requiring relatively more effort and energy, imposing a trade-off between controlling positive symptoms and the ability to socialise and participate in activities:

"Because my thoughts were racing in really weird directions, they thought that a more sedative tablet would be better for me. But, of course, then that meant that I wasn't going out very much. I wasn't socialising. I wasn't really doing the things that may have helped me". Hayley, Cornwall

For others, lack of motivation was seen as a side-effect of weight-gain associated with antipsychotic use.

"When I was lighter I was more active and doing loads of things and I had motivation and everything. And now like - my motivation - like before I had loads of motivation. Now that my motivation isn't really there. It's like someone has to push me to do things".

Aisha, Birmingham

\section{“A confidence thing"}

Lack of self-confidence was another explanation participants cited for decreased expression, motivation and sociability. For instance, Yasmin spoke about behaving during her episode of 
psychosis in ways that she afterward viewed as inappropriate. This led to crippling doubt about her ability to navigate even simple everyday activities and interactions:

"I don't talk to anybody that much and I haven't got confidence left in me, because I think, 'Oh, my God.' I'm not sure about things which I'm doing. Like, am I not, am I doing right or not, because, you know, like, when you're unwell, you don't realise, do you?".

Yasmin, Lancashire

Whilst Yasmin described a global lack of self-confidence, other participants lacked confidence in a specific domain. For instance, Clara discussed her reluctance to engage in “intellectual” conversations due to reduced confidence in her cognitive capacities:

"An intellectual conversation with someone, that scares me because I feel like I don't know. And perhaps that's a confidence thing. I know things that they don't know perhaps, but it just seems like I don't have that, that way of being able to process information or to capture the - to have that information that I had before". Clara, Cornwall

\section{Active avoidance}

Participants often presented decreased sociability as a deliberate strategy, intended to protect them from rejection or ridicule. Several participants spoke about deliberately cutting contact with friends or making fewer efforts to form new friendships than they would have done before experiencing psychosis:

"When I had the psychosis and the problems I cut myself off from a lot of people, I withdrew and I lost a lot of friends through that". John, Birmingham 
Some participants linked their social withdrawal to the stigma surrounding psychosis. Like Ben, most participants expressed that it was not stigma from others, but internalised stigma which contributed to their decision to withdraw:

"My relationship with, erm, quite a few of my friends has changed in a negative way, and it's not been because of prejudice or lack of understanding on their part, it's because at first I felt very ashamed, and I deliberately cut them out of my life". Ben, Birmingham

Participants were often acutely aware of negative media portrayals of psychosis and this fed fears about how others might perceive them. Aidan, who spoke about having lost contact with all his former friends, expressed that he believed others would find him 'disgusting' if he were to disclose his symptoms.

Shame and stigma were also important to some participants' decisions to avoid romantic relationships. Several participants shared Jennifer’s dilemma:

"It'd be really really hard to establish a relationship because you wouldn't know when to say to them, 'I've got schizophrenia' because if you leave it too late, they'll say, 'Oh why didn't you tell me, you've led me on.' And if you say it too soon, they'd never even speak to you because they'll just assume you're mad and it's very very, that's very difficult". Jennifer, Lancashire

A lack of romantic relationships in individuals with psychosis is sometimes considered indicative of diminished capacity for emotional closeness. However, Jennifer's account offers the alternative explanation that some who experience psychosis may have simply given up hope of establishing an intimate relationship due to the perceived barriers imposed by stigma. 
Some participants employed a strategy of avoidance in order to escape negative evaluation of their changed appearance following medication induced weight-gain. For instance, Clara explained that her weight increased rapidly whilst on antipsychotic medication and, as a result, she avoided social situations in order to protect herself from the critical gaze of others:

I had my episode and was in the ward in London, then came back down. No one knew what had happened to me, but I was huge ... I didn't want anyone to see me like that. I know it's sad, but I really didn't".

Clara, Cornwall

Clara described her fear that her sudden weight-gain would alert others to her use of antipsychotics, thus exposing her to potential stigma.

\section{Discussion}

In a purposive sample of EIP service-users who followed varied negative symptom trajectories during their first-episode of psychosis, experiences corresponding to the negative symptoms construct commonly featured in participant's pre-existing accounts of psychosis. Participants' narratives challenge the widespread framing of negative symptoms as passive manifestations of diminished capacity, revealing the varied personal meaning of reduced expression, motivation and sociability.

Several participants used the simile 'like a zombie' to describe their experience of having difficulties interacting with the world around them, evoking a sense of otherness. For some, this experience led them to feel remote not only from other people, but also from themselves. Such accounts suggests that European phenomenological approaches to psychosis (Bürgy, 2008) may continue to be of relevance in understanding the subjective experience of negative symptoms. These approaches suggest that negative symptoms are not inherent deficit states 
but are instead characterised by positive experiential disturbances stemming from core disturbances in the sense of self (Sass \& Parnas, 2003).

Participants offered varying explanations of the negative symptom-like experiences they described. Consistent with research carried out with individuals with more chronic psychosis (Boydell, Gladstone, \& Volpe, 2003; Le Lievre et al., 2011), reduced communication and lack of motivation were often viewed as medication side-effects. As such, it is possible that the experiences described by some participants do not relate to primary negative symptoms but to negative symptoms secondary to medication side-effects.

Some participants described decreased emotional experience, capacity for thought or drive as lying behind changes in their behaviour. This echoes Krupa et al.’s (2010) finding that some individuals recovering from psychosis describe a deadening of emotions and increased apathy, turning participation in previously valued activities and social interactions into experiences to be endured. Participants also identified lack of confidence as a reason for negative symptom-like behaviour. Previous psychotic symptoms and the perception of decreased cognitive capacities undermined participants’ confidence in their abilities, leading to decreased activity and interaction. This finding supports quantitative evidence that pessimistic assessments of cognitive and social capabilities may be implicated in negative symptom maintenance (Campellone, Sanchez, \& Kring, 2016; Oorschot et al., 2013).

Active avoidance was also frequently recounted. Several previous studies have identified withdrawal as a strategy used by individuals experiencing psychosis to minimise potential embarrassment or rejection (Boydell et al., 2003; Judge, Estroff, Perkins, \& Penn, 2008; Mauritz \& van Meijel, 2009; Redmond, Larkin, \& Harrop, 2010). The apparent contribution 
of internalised and perceived stigma to some participants' active avoidance is in accord with previous research suggesting that withdrawal is a common reaction to feeling excluded from society as a result of mental health problems (Boydell et al., 2003).

These findings highlight the role of agency in negative symptom presentations, echoing Corin's reframing of negative symptoms as 'positive withdrawal' (Corin, 1990): a recovery strategy characterised by the deliberate maintenance of distance from normative social roles and relationships. They also intersect with cognitive models of negative symptoms which contend that apparent deficit presentations are often underpinned by active psychological processes (Rector, Beck, \& Stolar, 2005; Staring, Ter Huurne, \& van der Gaag, 2013).

\section{Limitations}

Since the study used qualitative secondary analysis, participants were not specifically asked about their experience of negative symptoms. Had an interview schedule specifically designed to elicit accounts of negative symptoms been employed, further insights might have been gained. However the use of secondary data also conferred advantages, making it possible to observe the extent to which negative symptoms were brought up spontaneously and the explanatory frameworks used by participants themselves.

The timing of data collection could also be considered a limitation. Participants were interviewed for the first time towards the end of their time with EIP or following discharge, in some cases several years after their index episode. It is possible this hindered participants' ability to recall their experiences. However, time having passed since the onset of their psychosis might also have afforded participants more time to reflect on their experiences. 


\section{Clinical Implications}

The findings indicate the potential value of exploring clients' personal understandings of their negative symptoms and suggest that particular attention should be paid to the possible impact of medication side-effects, diminished internal experience, low self-confidence and avoidant coping strategies. Clinicians should also consider the possible contribution of internalised stigma to negative symptom presentations. That participants often described active psychological processes as underpinning the negative symptom-like experiences they described supports the potential for tailored psychological interventions to ameliorate negative symptoms. 


\section{References}

Austin, S. F., Mors, O., Secher, R. G., Hjorthøj, C. R., Albert, N., Bertelsen, M., ... Nordentoft, M. (2013). Predictors of recovery in first episode psychosis: the OPUS cohort at 10 year follow-up. Schizophrenia Research, 150, 163-8. https://doi.org/10.1016/j.schres.2013.07.031

Bernard, H. R. (2006). Research methods in anthropology: qualitative and quantitative approaches (4th ed.). Lanham: AltaMira Press.

Birchwood, M., Lester, H., McCarthy, L., Jones, P. B., Fowler, D., Amos, T., ... Marshall, M. (2014). The UK national evaluation of the development and impact of Early Intervention Services (the National EDEN studies): study rationale, design and baseline characteristics. Early Intervention in Psychiatry, 8, 59-67. https://doi.org/10.1111/eip.12007

Blanchard, J. J., \& Cohen, A. S. (2006). The structure of negative symptoms within schizophrenia: implications for assessment. Schizophrenia Bulletin, 32(2), 238-45. https://doi.org/10.1093/schbul/sbj013

Boydell, K. M., Gladstone, B. M., \& Volpe, T. (2003). Interpreting Narratives of Motivation and Schizophrenia: A Biopsychosocial Understanding. Psychiatric Rehabilitation Journal, 26(4), 422-6.

Boydell, K. M., Stasiulis, E., Volpe, T., \& Gladstone, B. M. (2010). A descriptive review of qualitative studies in first episode psychosis. Early Intervention in Psychiatry, 4, 7-24. https://doi.org/10.1111/j.1751-7893.2009.00154.x

Braun, V., \& Clarke, V. (2006). Using thematic analysis in psychology. Qualitative Research in Psychology, 3(2), 77-101.

Bürgy, M. (2008). The concept of psychosis: Historical and phenomenological aspects. Schizophrenia Bulletin, 34(6), 1200-10. https://doi.org/10.1093/schbul/sbm136

Campellone, T. R., Sanchez, A. H., \& Kring, A. M. (2016). Defeatist Performance Beliefs, Negative Symptoms, and Functional Outcome in Schizophrenia: A Meta-analytic Review. Schizophrenia Bulletin. https://doi.org/10.1093/schbul/sbw026

Corin, E. E. (1990). Facts and meaning in psychiatry. An anthropological approach to the lifeworld of schizophrenics. Culture, Medicine and Psychiatry, 14, 153-88. https://doi.org/10.1007/BF00046659

Danermark, B., Ekström, M., Jakobsen, L., \& Karlsson, J. C. (2002). Explaining Society: Critical realism in the social sciences. London: Routledge.

Engqvist, I., \& Nilsson, K. (2013). Experiences of the first days of postpartum psychosis: an interview study with women and next of kin in Sweden. Issues in Mental Health Nursing, 34(2), 82-9. https://doi.org/10.3109/01612840.2012.723301

Gee, B., Hodgekins, J., Fowler, D., Marshall, M., Everard, L., Lester, H., ... Birchwood, M. (2016). The course of negative symptom in first episode psychosis and the relationship with social recovery. Schizophrenia Research, 174, 165-71. https://doi.org/10.1016/j.schres.2016.04.017

Heaton, J. (2004). Reworking Qualitative Data. London: Sage Publications.

Hirschfeld, R., Smith, J., Trower, P., \& Griffin, C. (2005). What do psychotic experiences mean for young men? A qualitative investigation. Psychology and Psychotherapy, 78, 
249-70. https://doi.org/10.1348/147608305X25865

Hodgekins, J., Birchwood, M., Christopher, R., Marshall, M., Coker, S., Everard, L., ... Fowler, D. (2015). Investigating trajectories of social recovery in individuals with first episode psychosis: a latent class growth analysis. The British Journal of Psychiatry, 207(6), 536-43. https://doi.org/10.1192/bjp.bp.114.153486

Irwin, S., \& Winterton, M. (2011). Debates in Qualitative Secondary Analysis: Critical Reflections. ESRC Timescapes Working Paper Series No.4. Retrieved from http://www.timescapes.leeds.ac.uk/assets/files/WP4-March-2011.pdf

Judge, A. M., Estroff, S. E., Perkins, D. O., \& Penn, D. L. (2008). Recognizing and responding to early psychosis: a qualitative analysis of individual narratives. Psychiatric Services, 59(1), 96-9. https://doi.org/10.1176/appi.ps.59.1.96

Krupa, T., Woodside, H., \& Pocock, K. (2010). Activity and social participation in the period following a first episode of psychosis and implications for occupational therapy. The British Journal of Occupational Therapy, 73(1), 13-20. https://doi.org/10.4276/030802210X12629548272628

Lambert, H., \& McKevitt, C. (2002). Anthropology in health research: from qualitative methods to multidisciplinarity. BMJ, 325(7357), 210-213. https://doi.org/10.1136/bmj.325.7357.210

Larsen, J. A. (2004). Finding Meaning in First Episode Psychosis: Experience, Agency and Cultural Repertoire. Medical Anthropology Quarterly, 18(4), 447-71.

Le Lievre, J. A., Schweitzer, R. D., \& Barnard, A. (2011). Schizophrenia and the progression of emotional expression in relation to others. Qualitative Health Research, 21(10), 1335-46. https://doi.org/10.1177/1049732311406448

Luhrmann, T. M., Padmavati, R., Tharoor, H., \& Osei, A. (2015). Differences in voicehearing experiences of people with psychosis in the USA, India and Ghana: interviewbased study. The British Journal of Psychiatry, 206(1), 41-4. https://doi.org/10.1192/bjp.bp.113.139048

Lyne, J., O’Donoghue, B., Owens, E., Renwick, L., Madigan, K., Kinsella, A., ... O’Callaghan, E. (2012). Prevalence of item level negative symptoms in first episode psychosis diagnoses. Schizophrenia Research, 135, 128-33. https://doi.org/10.1016/j.schres.2012.01.004

Mauritz, M., \& van Meijel, B. (2009). Loss and grief in patients with schizophrenia: on living in another world. Archives of Psychiatric Nursing, 23(3), 251-60. https://doi.org/10.1016/j.apnu.2008.06.006

McCarthy-Jones, S., Marriott, M., Knowles, R., Rowse, G., \& Thompson, A. R. (2013). What is psychosis? A meta-synthesis of inductive qualitative studies exploring the experience of psychosis. Psychosis, 5(1), 1-16. https://doi.org/10.1080/17522439.2011.647051

Notley, C., Green, G., \& Marsland, L. (2014). Qualitative Analysis. In D. M. Walker (Ed.), An Introduction to Health Services Research (pp. 327-42). London: Sage Publications.

Oorschot, M., Lataster, T., Thewissen, V., Lardinois, M., Wichers, M., van Os, J., ... MyinGermeys, I. (2013). Emotional experience in negative symptoms of schizophrenia - no evidence for a generalized hedonic deficit. Schizophrenia Bulletin, 39(1), 217-25. https://doi.org/10.1093/schbul/sbr137

QSR International. (2012). NVivo Qualitative Data Analysis Software.

Rector, N. A., Beck, A. T., \& Stolar, N. (2005). The Negative Symptms of Schizophrenia: A 
Cognitive Perspective. Canadian Journal of Psychiatry, 50(5), 247-57.

Redmond, C., Larkin, M., \& Harrop, C. (2010). The personal meaning of romantic relationships for young people with psychosis. Clinical Child Psychology and Psychiatry, 15(2), 151-70. https://doi.org/10.1177/1359104509341447

Sass, L. A., \& Parnas, J. (2003). Schizophrenia, Consciousness, and the Self. Schizophrenia Bulletin, 29(3), 427-44. https://doi.org/10.1093/oxfordjournals.schbul.a007017

Singh, S. P., Croudace, T., Amin, S., Kwiecinski, R., Medley, I., Jones, P. B., \& Harrison, G. (2000). Three-year outcome of first-episode psychoses in an established community psychiatric service. British Journal of Psychiatry, 176, 210-6. https://doi.org/10.1192/bjp.176.3.210

Staring, A. B. P., Ter Huurne, M.-A. B., \& van der Gaag, M. (2013). Cognitive Behavioral Therapy for negative symptoms (CBT-n) in psychotic disorders: a pilot study. Journal of Behavior Therapy and Experimental Psychiatry, 44(3), 300-6. https://doi.org/10.1016/j.jbtep.2013.01.004

Sterk, B., Winter van Rossum, I., Muis, M., \& de Haan, L. (2013). Priorities, satisfaction and treatment goals in psychosis patients: an online consumer's survey. Pharmacopsychiarty, 46(3), 88-93.

Velthorst, E., Koeter, M., van der Gaag, M., Nieman, D. H., Fett, A.-K. J., Smit, F., ... de Haan, L. (2015). Adapted cognitive-behavioural therapy required for targeting negative symptoms in schizophrenia: meta-analysis and meta-regression. Psychological Medicine, 45(3), 453-65. https://doi.org/10.1017/S0033291714001147

Werbart, A., \& Levander, S. (2005). Understanding the incomprehensible: private theories of first-episode psychotic patients and their therapists. Bulletin of the Menninger Clinic, 69(2), 103-36. https://doi.org/10.1521/bumc.69.2.103.66507 


\section{Tables}

Table 1. Sample demographic characteristics and mean negative symptom severity scores

\begin{tabular}{|c|c|c|c|c|c|c|}
\hline \multirow[t]{2}{*}{ Pseudonym $^{a}$} & \multirow[t]{2}{*}{ Study Site } & \multirow[t]{2}{*}{ Ethnicity } & \multirow[t]{2}{*}{ Age $^{\mathrm{b}}$} & \multicolumn{3}{|c|}{ Mean Negative Symptom Score } \\
\hline & & & & Baseline & $6 \mathrm{M}$ & 12M \\
\hline Daniel & Norfolk & White British & 20 & 4.00 & 4.43 & 4.00 \\
\hline Max & Cheshire & White British & 27 & 4.00 & 3.43 & 2.71 \\
\hline Nathan & Birmingham & White British & 26 & 3.43 & 3.29 & 2.57 \\
\hline Yasmin & Lancashire & Asian Pakistani & 28 & 1.57 & 3.29 & 2.57 \\
\hline Tom & Cambridgeshire & White British & 20 & 1.71 & 2.29 & 2.14 \\
\hline Hayley & Cornwall & White British & 28 & 3.00 & 2.86 & 2.86 \\
\hline John & Birmingham & White British & 31 & 2.57 & 3.00 & 2.57 \\
\hline Jacob & Birmingham & Black Caribbean & 28 & 3.43 & 3.43 & 1.00 \\
\hline Aisha & Birmingham & Asian Pakistani & 28 & 3.29 & 2.00 & 1.43 \\
\hline Oliver & Cornwall & White British & 30 & 3.14 & 1.29 & 2.00 \\
\hline Stacey & Cornwall & White British & 27 & 4.29 & 2.29 & 1.29 \\
\hline Aidan & Norfolk & White British & 25 & 3.00 & 3.43 & 2.14 \\
\hline Steve & Lancashire & White British & 27 & 2.86 & 3.71 & 2.14 \\
\hline Philip & Norfolk & White British & 37 & 1.00 & 1.29 & 1.29 \\
\hline Nazir & Lancashire & Other Asian & 21 & 2.29 & 2.29 & 1.86 \\
\hline Alexander & Devon & Other White & 32 & 1.00 & 2.57 & 1.00 \\
\hline Shelly & Birmingham & Black Caribbean & 28 & 1.29 & 1.57 & 1.29 \\
\hline Isabella & Cambridgeshire & White/Asian & 35 & 1.57 & 1.14 & 1.14 \\
\hline Jennifer & Lancashire & White British & 30 & 2.14 & 1.57 & 1.00 \\
\hline Ben & Birmingham & White/Caribbean & 27 & 2.43 & 1.57 & 1.14 \\
\hline Kelly & Norfolk & White British & 22 & 1.43 & 1.57 & 1.71 \\
\hline Clara & Cornwall & White/African & 30 & 2.14 & 1.00 & 1.00 \\
\hline Jack & Cambridgeshire & White Irish & 29 & 1.71 & 1.00 & 1.00 \\
\hline Callum & Cheshire & White British & 27 & 1.14 & 1.00 & 1.00 \\
\hline
\end{tabular}

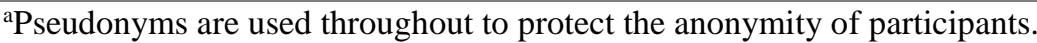

${ }^{\mathrm{b}}$ Age at initial interview.

'Mean negative symptoms score ( $\min 1$; max 7 ) for the seven PANSS items ('blunted affect' (N1), 'emotional withdrawal' (N2), 'poor rapport' (N3), 'passive social withdrawal' (N4), and 'lack of spontaneity and flow of conversation' (N6), 'motor retardation' (G7) and 'active social avoidance' (G16)) found to indicate the negative symptoms construct in a factor analysis of data from the EDEN cohort. 